\title{
Validation of the Spanish Version of the Inventory of Suicide Orientation - ISO 30 in Adolescent Students of Educational Institutions in Medellin - Colombia
}

\author{
Ramón E. Paniagua-Suárez ${ }^{1, *}$, Carlos M. González-Posada ${ }^{2} \&$ Sandra M. Rueda-Ramírez ${ }^{1}$ \\ ${ }^{1}$ Facultad Nacional de Salud Pública, Universidad de Antioquia, Medellín, Colombia \\ ${ }^{2}$ Instituto de Educación Física, Universidad de Antioquia, Medellín, Colombia \\ *Correspondence: Facultad Nacional de Salud Pública, Universidad de Antioquia, Medellín, Colombia. Tel: \\ 57-4-219-6894. E-mail: ramon.paniagua@udea.edu.co
}

Received: July 13, 2016

Accepted: July 27, $2016 \quad$ Online Published: August 12, 2016

doi:10.5430/wje.v6n4p22

URL: http://dx.doi.org/10.5430/wje.v6n4p22

\begin{abstract}
Inventory of Suicide Orientation - ISO 30, it is a self-report scale that measures risk of adolescents suicide orientation. Although the risk of adolescents suicide is on the public agenda in Colombia actually, there is no study to analyze the psychometric properties of ISO 30 , and for this reason, the present study is conducted with a random sample of 604 adolescent students (48\% were male and 52\% female with an average age of 14 and a deviation of 1.9 years). Methods: A confirmatory factor analysis was performed; reliability is checked by the Cronbach's alpha and correlation item-subconstruct to which it belongs; The test-retest reliability and concurrent validity with the RFL-A validated scale in Colombia with teenage school people is verified. AMOS 16.0 and SPSS version 20.0 for data processing was used. Results: this population was confirmed in the same factorial structure of the original scale; so does the internal consistency for the 30 items and the correlation of each item with its own subconstruct: social isolation and marginalization, low self-esteem, inability to manage emotions, suicidal ideation and hopelessness. Conclusion: The Inventory of Suicide Orientation - ISO 30 Spanish version, is a useful questionnaire and appropriate to diagnose the risk of suicidal orientation (which is a prelude to suicidal idea) in the adolescents students people in Medellin city.
\end{abstract}

Keywords: suicide orientation; adolescent; validation scale; mental health

\section{Introduction}

Suicide, as a matter of public health, has been introduced in almost all public health agendas in countries of the world, with the aim to establish public policies to address this situation; in fact, it is estimated that by 2020, about 1.5 million people around the world could commit suicide, and ten times this quantity, could have a try (Hoven, Mandell, $\&$ Bertolote, 2010). Although they have implemented efforts to train primary caregivers, establish hotlines, or have staff trained to the know how to answer in case to detect signs or symptoms of possible suicide attempt (Hoven, Wasserman, Wasserman, \& Mandell, 2009), the problem goes beyond taking immediate strategies, for example, taking in account the policies established by governments on the issue of mental health, in order to observe the effect of investing in prevention programs to decrease suicide rates and their relation with other mental disorders (Ross, Yakovlev, \& Carson, 2012); in this sense, and from an economic perspective of public health, it can be seen how the increase of unemployment is associated with more medical aid benefices and high expenditures on health care (Pellegrini \& Rodriguez-Mongui, 2013), or how fiscal austerity may lead to situations related ideas or suicide attempts (Antonakakis \& Collins, 2014) or demonstrate that the social support avoiding people isolation, are important to prevent suicidal acts (Rajkumar, Brinda, Duba, Thangadurai, \& Jacob, 2013).

While suicide rates among the elderly have been reduced in many countries, in young people they have increased; It is the third leading cause of death among 15 to 34 years worldwide (Pulido, Higuera, Ortega, \& Salamanca, 2009). As problematic focused on teenagers, some research of international order found that suicidal thoughts or attempts often are related to bad family functioning or the perceptions of adolescents about their family and the role played in 
it (Lipschitz, Yen, Weinstock, \& Spirito, 2012); often, these roles have to do with parenting patterns in childhood and subsequent performance when they assume responsibilities in their adolescent stage (Cero \& Sifers, 2013); when parenting patterns are positive, there is decreased risk in situations of suicidal thoughts or ideas. In the national context, epidemiological studies to determine the probability of suicide risk and / or mental illness with associates factors in students of the Bogota (Colombia), have shown that depression, low self-esteem, family dysfunction, female gender, greater than or equal to 15 years of age and domestic violence are risk factors associated with suicide; good family relationships are associated with lower risk (Pérez-Olmos, Tellez, Velez, \& Ibanez-Pinilla, 2012). If you try to establish national studies from a gender perspective, are vulnerabilities in females; a comparative study of suicidality among adolescents and adults in the city of Bucaramanga (Colombia), shows that adolescents with suicide risk were more frequently women, had higher percentage of suicide attempts and less serious mental health problems than adults (Rueda, Rangel, Castro-Wheel, \& Camacho, 2010).

The concerns also relates to children's vulnerability, according some studies shows that patients under 12 generally have the first attempt by poisoning with drugs. Is evident The need to identify and diagnose suicidal thoughts in adolescents; this is not an easy task because there are many instruments designed for such purposes; in Medellin city, the work with problems about mental health, specifically adolescent suicide, arises from 1990 starts with validation of scales to diagnose the signs and symptoms indicating depression or more specific such as psychiatric patients, in order to determine the lifetime prevalence factors in people, associated with suicidal ideation and suicide attempts (Garcia et al., 2009).

Teen suicide is an issue that is on the public agenda in Medellin, because health services offered by the Mayor of the city in the communes of Medellín, have been found suicide attempts among these young people. In 2006 began the mental health studies in adolescents students with a research from the Universidad de Antioquia in the northeastern zone of Medellin (Paniagua, Gonzalez, \& Montoya, 2006), and to all adolescent students in the city, the Mayor of Medellin entrusts the University CES two studies, in 2007 and 2010 (Montoya, Torres Zapata, Garro, Hurtado \& Villegas, 2010). Given the absence of validated scales that measured risk of suicide in this people, was identified and selected the Inventory of Suicide Orientation - 30 (ISO 30) (King \& Kowalchuck, 1994), scale self-report developed in 1994 and applied in ages 13 to 18 years old, with good consistency between the ages of 12 and 19; ISO 30 has the purpose of identifying adolescents who are at risk of suicide and measures the strength of their suicidal orientation, which provides objective and validated scientific information to identify adolescents who are going through a particular crisis and require clinical intervention or treatment by a professional. The purpose of validation in the local context, was oriented to determine the psychometric properties of the Spanish version of ISO 30 instrument, in a sample of young people school of northwestern area of Medellin-Colombia, aged between 12 and 19 years old.

\section{Methods}

The northwestern area of Medellin is divided into three districts: Castilla, Doce de Octubre and Robledo; they comprise 73 neighborhoods where the predominant medium-low stratum, and to a lesser extent, the lower stratum. It was considered as an observation unit teenager who was enrolled and studying in any of grades sixth through eleventh in any of the educational institutions located in the northwest area, and that had an age between 12 and 19 years old at the time of application of this instrument. The sample collection was conducted between May and June 2014.

A random sample was designed, taking as variable of interest the proportion of adolescent students with some risk of suicide, with a confidence level of $95 \%$ and an absolute error of 3.5\%; 604 students participated in the 55 educational institutions in three districts in the northwestern area, where $48 \%$ were male and $52 \%$ female, with an average age of 14 years old, and a deviation of 1.9 years compared to the average age. The refusal to participate in the sample was $0.05 \%$.

The instrument used to collect information was the Inventory of Suicide Orientation (ISO 30) Spanish version, which measures orientation risk of suicidal adolescents. ISO 30 contains 30 items, grouped into five sub-constructs: suicidal ideation, hopelessness, social isolation and marginalization, low self-esteem and inability to control emotions; each of them with six items where responses describe how the person has been thinking in the last six months. The response options are: 1. "Sure I disagree", 2. "I generally disagree", 3. "I generally agree" and 4. "sure I agree". Among the 30 items, there are six "critical items" which are associated with an increased risk of suicidal ideation; each response items are scored from 0-3 and both the total score and the score of the critical items classified the risk of suicidal orientation in high (greater than 45 points), moderate (30 to 44 points) or low (lower score 30 ). At the time of application, you can identify a teenager at high risk for suicide orientation if says yes to three or more items 
of the six critical items. The design of the scale was conducted by experts who were based in the diagnostic manual, DSM IV.

The internal consistency observed the ISO 30 in two groups, a clinic and other nonclinical of high school students, was found to be internally consistent ( $a=0.92$, and $a=0.90$ respectively). Cronbach's alpha for the critical elements score was $a=0.79$ in the clinic sample and $a=0.78$ in the student's sample (Carretero \& Pérez, 2005).

To perform the validation of the Spanish version of ISO 30, was taken into account the following (Carretero \& Pérez, 2005), (Sanchez \& Echeverry, 2004): verify construct validity, reliability estimated by Cronbach's alpha for the total scale, the correlation between the total score of the item and the total obtained in the dimension to which it belongs, the test-retest reliability and criterion validity, which in this case is a concurrent validity because compared with other scale that measures the same.

\subsection{Construct Validity}

It is to verify that the theoretical structure of ISO 30 corresponds to the empirical structure, and which is considered a sample of 604 students (meets the criterion at least 10 individuals for each item of the scale (Carretero \& Pérez, 2005), with which is designed a Structural Equation Model or Confirmatory Factorial Analysis (FCA) to verify that the items homogeneously fit to the five sub-constructs; on the same sample, we proceed to estimate three alternative models (with $n=200$ randomly selected from the initial sample) to compare the measures of goodness of fit. test. The structural model of the ISO-30 was estimated for each new sample in order to obtain the estimated parameters goodness of fit test (Carretero \& Pérez, 2005).

The goodness of fit test for the proposed models was assessed using indicators of average residual (Residual Root Mean, RMR) and root mean square error of approximation (Root Mean Square of Error of Approximation, RMSEA). Other indicators used were relative adjustment index goodness of fit (General Fit Index, GFI), the corrected index goodness of fit test (Adjusted General Fit Index, AGFI) and the index of goodness of fit of parsimony (Parsimonious General Fit Index, PGFI) (Landero \& González, 2006). The reference values are for the RMR values between 0 and 1, where 0.0 indicates perfect goodness of fit and a value of 0.05 or less suggests good fit; GFI between 0.90 and 0.95, for AGFI greater than 0.9 as for the PGFI. The RMSEA values should be less than 0.08 to have an acceptable or 0.05 close fit to have a good fit.

\subsection{Reliability}

It was determined by a single administration of ISO 30 (Carretero \& Pérez, 2005) by the index of internal consistency, Cronbach's alpha coefficient. The minimum reliability calculated by the internal consistency of 0.80 should be appropriate reliability, even for research purposes without affecting the participants is around 0.70 (Carretero \& Pérez, 2005).

\subsection{Correlation Item-Sub-Constructs}

The score of each item with the score sub-construct to which belongs, are related with: social isolation and marginalization, low self-esteem, inability to control emotions, suicidal ideation and hopelessness. The Spearman correlation coefficient was calculated and found that the correlation was different from zero for a $\mathrm{p}$ value less than $5 \%$.

\subsection{Test-Retest Reliability}

ISO 30 was applied to a sample of 55 randomly selected students in the initial sample, and four days the risk of suicidal orientation with the ISO 30 was measured for the second time (a larger sample than 50 preserves the original factor structure (Hair, Anderson, Tatham, \& Black, 1999). The reliability test -retest ISO 30 is given if the correlation coefficient between the scores of the first application and the second is statistically different from zero.

\subsection{Criterion Validity}

In the second application in addition to the ISO 30, the risk of suicide Inventory was measured Reasons For Live in adolescents (RFL-A). To determine the criterion validity, it was verified that the ISO 30 scale work like another instrument to find external evidence of validity with external criteria using the RFL-A instrument.

Reasons for Living Inventory for adolescents, was developed by Agustine Osman et al in 1996 (Moreno, 2008). It is an instrument designed to evaluate cognitive factors that help individuals to survive in facing difficult and adverse situations. It consists of 32 items grouped in five factors: optimism ahead (seven items), concerns related to suicide (six items), family alliance (seven items), acceptance or peer support (six items) and self-acceptance (six items). The response format likert has six response options:1) no at all important; 2) quite unimportant; 3) somewhat unimportant; 
4) somewhat important; 5) quite important; 6) extremely important. The total score is obtained by adding the scores on each item determining levels of reasons for living as follows: Very low reasons to live (up to 20th percentile), Low reason to live (from the 21 to 40 percentile) average level of reasons for living (from 41 to 60 percentile) and optimal level reasons for living (from 61 th percentile).

The internal consistency of the RFL-A observed in two samples, one for high school students, referring to the non-clinical population and other adolescent people psychiatric patients (clinical), was as follows: Future optimism $\alpha$ $=0.92$, concerns related to suicide $\alpha=0.93, \alpha=0.94$ Family Alliance, peer acceptance and support $\alpha=0.89$, and self-acceptance $\alpha=0.94$. For total RFL-A $\alpha=0.96$ was obtained in non-clinical sample and $\alpha=0.97$ in the clinical sample. Validation held in Colombia the RFL-A teen adapted to the Spanish school population, a $\alpha=0.91$ was obtained (Moreno, 2008). Therefore it is suggested that the RFL-A has adequate reliability and validity measures, making it a potentially useful tool in assessing adolescent's suicidal behavior.

The statistical relationships between ISO 30 and the RFL-A level, through the correlation coefficient between total scores of both scales were analyzed. Another evaluation was used to verify the concurrence of scales, was the Kappa concordance index from a table $2 \times 2$ contingency. Guaranteed confidentiality and informed consent was taken to each adolescent in the study. For minors, informed parents to consent was requested, following the recommendations of the ethics committee of the National School of Public Health at the University of Antioquia, which assessed the research as of minimal risk. For processing statistical data used software: AMOS version 16.0 and SPSS version 20.0 .

\section{Results}

The goodness of fit measures displayed in Table 1 FCA models into consideration, meet the criteria of having a root mean square error approximation (RMSEA) less than 0.08 , which explains a good fit models. Furthermore, measures for the three alternative models reveals that they are further from the theoretical reference values, and therefore none of these alternative measures shows better than those obtained in the initial model, called reference model $(\mathrm{n}=604)$.

Table 1. Measures of Goodness of Fit Model* for Confirmatory Factor Analysis (CFA) for the Items of ISO 30 in the Reference Model

\begin{tabular}{lllll}
\hline Sample & RMR & GFI & AGFI & PGFI \\
\hline $\mathrm{n}=604^{* *}$ & 0.086 & 0.847 & 0.819 & 0.719 \\
$\mathrm{n}_{1}=200$ & 0.093 & 0.779 & 0.739 & 0.661 \\
$\mathrm{n}_{2}=200$ & 0.101 & 0.775 & 0.735 & 0.658 \\
$\mathrm{n}_{3}=200$ & 0.086 & 0.847 & 0.819 & 0.719 \\
\hline
\end{tabular}

* In all samples the RMSEA was below 0.08. ** Reference sample

In evaluating the model of factorial structure of ISO 30, the Spanish version (Figure 1) showed rates of goodness of fit in the confirmatory factor analysis (CFA) considered appropriate (Table 1, reference sample), which indicates an adequate level of association of the items in each sub-constructs: hopelessness, worthlessness, inability to control emotions, social isolation and marginalization, and suicidal ideation in adolescents. 


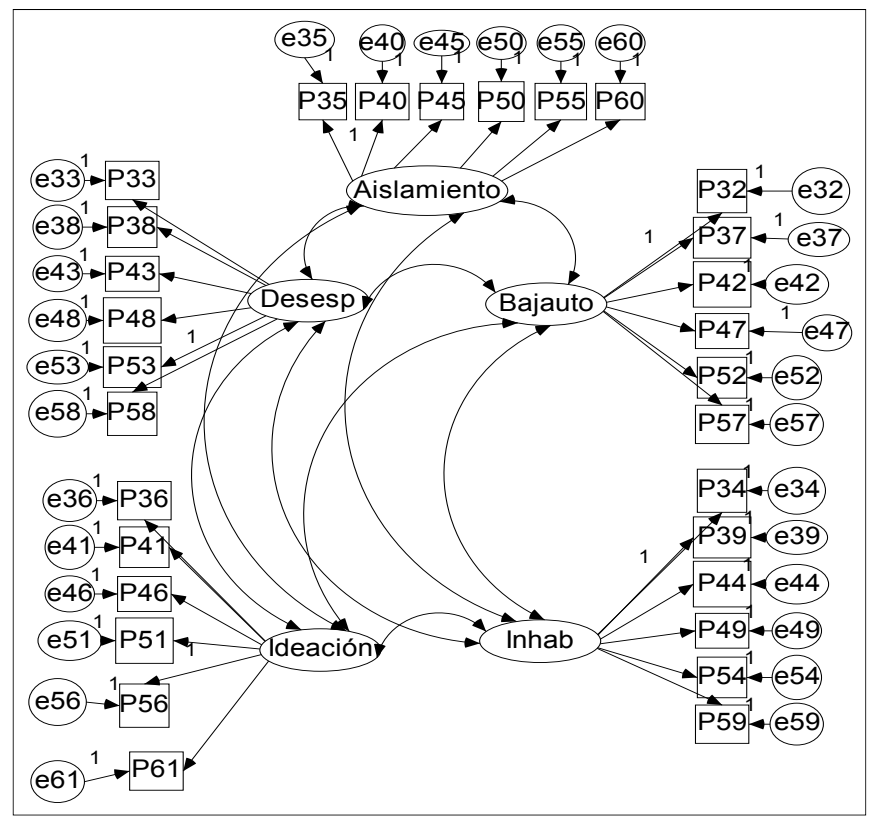

Figure 1. Diagram of Structural Relationship of Five Factors: Social Isolation (Aislamiento), Hopelessness (Desesp), Worthlessness (Bajauto), Inability to Control Emotions (Inhab) and Suicidal Ideation ISO 30 (Ideación).

Internal consistency, Cronbach's alpha following presents an overall index of 0.826, close to 1 (high internal consistency), indicating good internal consistency of the scale, verifying that the items of ISO 30 are correlated, and therefore the instrument is reliable to identify the level of risk of suicidal orientation of the adolescents.

The item-scale correlations to which it belongs, is significant between the items and the following sub-constructs: social isolation, low self-esteem, inability to control emotions, suicidal ideation and hopelessness with which it is evident that the ISO 30 has a good structure (Table 2).

Table 2. Spearman Correlations between the Size or Sub-Construct and Item Belongs ISO 30

\begin{tabular}{|c|c|c|c|c|c|c|c|}
\hline \multirow{3}{*}{ Social isolation } & ítem & P35 & P40 & $\mathrm{P} 45$ & P50 & P55 & P60 \\
\hline & Coefficient & $0.466^{* *}$ & $0.643 * *$ & $0.483 * *$ & $0.674 * *$ & $0.604 * *$ & $0.621 * *$ \\
\hline & P Value & 0.000 & 0.000 & 0.000 & 0.000 & 0.000 & 0.000 \\
\hline \multirow{3}{*}{ Low self-esteem } & ítem & P32 & P37 & $\mathrm{P} 42$ & P47 & P52 & P57 \\
\hline & Coefficient & $0.470 * *$ & $0.552 * *$ & $0.374 * *$ & $0.634 * *$ & $0.674 * *$ & $0.662 * *$ \\
\hline & P Value & 0.000 & 0.000 & 0.000 & 0.000 & 0.000 & 0.000 \\
\hline \multirow{3}{*}{ Inability to control emotions } & ítem & P34 & P39 & P44 & P49 & P54 & P59 \\
\hline & Coefficient & $0.334 * *$ & $0.422 * *$ & $0.265 * *$ & $0.459 * *$ & $0.481 * *$ & $0.393 * *$ \\
\hline & P Value & 0.000 & 0.000 & 0.000 & 0.000 & 0.000 & 0.000 \\
\hline \multirow{3}{*}{ Suicidal ideation } & ítem & P36 & P41 & P46 & P51 & P56 & P61 \\
\hline & Coefficient & $0.464 * *$ & $0.640 * *$ & $0.649 * *$ & $0.667 * *$ & $0.678 * *$ & $0.665^{* *}$ \\
\hline & P Value & 0.000 & 0.000 & 0.000 & 0.000 & 0.000 & 0.000 \\
\hline \multirow{4}{*}{ Hopelessness } & ítem & P33 & P38 & P43 & P48 & P53 & P58 \\
\hline & Coefficient & $0.491 * *$ & $0.570 * *$ & $0.512 * *$ & $0.521 * *$ & $0.595 * *$ & $0.630 * *$ \\
\hline & P Value & 0.000 & 0.000 & 0.000 & 0.000 & 0.000 & 0.000 \\
\hline & $\mathrm{n}$ & 604 & 604 & 604 & 604 & 604 & 604 \\
\hline
\end{tabular}

** It is significant at $1 \%$.

The test-retest reliability between total scores of the first and second application, showed a Pearson correlation coefficient significantly different from zero with a value of 0.780 ( $p$-value $=0.000$ ), determining a good stability over time of the ISO 30 scale. 
Criterion validity or concurrent assessment is verified by the correlation coefficient between total scores of the scales into consideration. As the total scores of the ISO 30 and RFL-A scales is adjusted to a normal, the Pearson correlation coefficient which is equal to is calculated -0.659 ( $\mathrm{p}$-value $=0.000$ ), which means that the correlation is significant; the negative sign indicates that both scales are inversely proportional; while a high score in the ISO 30 is problematic because it indicates risk of suicide, in the RFL-A suicide risk represents the low scores.

Concordance test was also evaluated by Kappa coefficient $=0.546(\mathrm{p}$-value $=0.000)$, which showed that there is agreement between the presence of suicide risk as the ISO 30 and the presence of suicide risk as the RFL-A.

\section{Discussion}

Inventory of Suicide Orientation ISO-30, is a questionnaire that can be used in young people students of Medellin for diagnosing risk of suicidal orientation which is a prelude of suicidal ideation. In the area of public health, it is important to prevent the occurrence of suicidal idea because it prevents a possible suicidal event, which affects teenagers mental health, their families and the context in which it operates.

In first place, the factorial validation of the structure of ISO 30 using a confirmatory factor analysis (Joseph, Rolph, Ronald, \& William, 2004), shows that the results of the goodness of fit indices of its sub-constructs and items are not within of ideal reference parameters, but it showed how the current structure (of the sub-constructs and items) for the sample, it is better than generation of any other alternative of random structure.

According to the goodness of fit test obtained in other studies (Trujillo, Pineda-Arango, Puerta, Lopera, Aguirre, \& et al., 2010), the values of the measures of goodness of fit of the model concerning the Inventory of Suicide Orientation ISO-30 to the 604 adolescent students, are suitable.

A value around 0.70 in the reliability coefficients instrument is considered respectable and it is certainly desirable (Henerson, Morris \& Fitz-Gibbon, 1987); with respect to consistency analysis, the authors of the ISO - 30, verified an Alfa value of 0.90 in 768 students between 12-18 years old (King \& Kowalchuck, 1994) and a psychometric study conducted on ISO 30 held in the city of Buenos Aires on 642 adolescents between 13 and 20 years old, an alpha of 0.88 (Fernandez \& Casullo, 2006) was demonstrated.

According to what was observed in this study was obtained an internal consistency of 0.83 , that while it is below the above values, suggesting good consistency between the items instrument both variability and correlated these with the dimensions that they belong, still suitable ISO 30 scale for assessing the level of risk of suicidal orientation.

In the first and second application was obtained, respectively, an internal consistency for the 30 items of 0.865 and 0.874 which coincides with the results reported above and in which the benefits of the instrument it is ensured. The results of the two applications of ISO 30 are consistent in terms of the conservation of the original factorial structure and internal consistency and suggest that suicide risk measurements obtained in adolescents from Medellin, are equally reliable as those obtained by creators of ISO 30 in American teenagers.

\section{Conclusion}

When comparing performance of the ISO - 30 against different scale as the RFL-A, it is observed to be reliable for measuring risk of suicidal orientation. Both the correlation as the concordance of the two scales validates the ISO 30 instrument as an useful tool to identify an adolescent at risk of suicide.

These findings have an important significance for public health in the city of Medellin, because they provide us another scale to measure risk of suicide in adolescent students, an issue that is on the public agenda of the municipal authorities.

The weakness of this study is the non-implementation of a clinical test to identify risk of suicidal orientation because the costs, student's mobility, and time of conducting research into the educational institution, they did not allowed. The methodology used in the validation gives the strength to study because it is according with international standards defined in these cases.

\section{Acknowledgements}

Students, teachers and administrators of educational institutions in the northwestern area of Medellin.

This article is the result of research conducted with the financial support of the sustainability strategy committee from 2013 to 2014 for the development of research - CODI-Universidad de Antioquia. 
The authors declare no particular interest or present conflicts of interest in the development and publication of this work.

\section{References}

Antonakakis, N., \& Collins, A. (2015). The impact of fiscal austerity on suicide: On the empirics of a modern Greek tragedy. Social Science and Medicine Journal, 112, 39-50.

Carretero H., \& Pérez C. (2007). Normas para el desarrollo y revisión de estudios instrumentales. International Journal of Clinical and Health Psychology, 7(3), 863-882.

Cero I., \& Sifers SK. (2013). Parenting behavior and the Interpersonal-Psychological Theory of Suicide: A mediated moderation analysis with adolescents. Journal of Affective Disorders, 150(3), 987-992. http://dx.doi.org/10.1016/j.jad.2013.05.025

Fernández M., \& Casullo M. (2006). Validación factorial de una escala para evaluar riesgo suicida. RIDEP, 21(1), 9-22.

García J et al. (2009). Validación del Inventario de razones para vivir (RFL) en sujetos con conducta suicida de Colombia. Rev. colomb. psiquiatr, 38(1), 66-84.

Hair J., Anderson R., Tatham R., \& Black W. (1999). Análisis multivariante (5th ed.). Madrid. Pearson-Prentice Hall.

Henerson ME., Morris LL., \& Fitz-Gibbon CT. (1987). How to Measure Attitudes. Newbury Park, CA. Sage Publications.

Hoven CW., Mandell DJ., \& Bertolote JM. (2010). Prevention of mental ill-health and suicide: Public health perspectives. European Psychiatry, 25(5), 252-256. http://dx.doi.org/10.1016/j.eurpsy.2010.01.011

Hoven CW., Wasserman D., Wasserman C., \& Mandell DJ. (2009). Awareness in nine countries: A public health approach to suicide prevention. Legal Medicine, $11(\operatorname{supl} 1)$ 13-17. http://dx.doi.org/10.1016/j.legalmed.2009.01.106

King D., \& Kowalchuck B. (1994). Inventory of suicide orientation -30, ISO 30. Minneapolis: National Computer Systems, INC.

Landero HR y González RM. (2006). Estadística con SPSS. Metodología de la Investigación. México: Trillas.

Lipschitz JM., Yen S., Weinstock LM., \& Spirito A. (2012). Adolescent and caregiver perception of family functioning: Relation to suicide ideation and attempts. Psychiatry Research, 200(2-3), 400-403. http://dx.doi.org/10.1016/j.psychres.2012.07.051

Montoya LP., Torres Y., Zapata MA., Garro C GI., \& Hurtado, Villegas G. (2009). Segundo estudio de salud mental del adolescente - Medellín. Rev Salud Pública de Medellín 2010, 4(2), 23-40.

Moreno AM. (2008). Propiedades psicométricas del inventario de razones para vivir (RFL-A) adaptado al español en una muestra de estudiantes de bachillerato de la ciudad de San juan de Pasto. [Trabajo de grado en psicología]. Retrived from http://190.66.7.6:8085/atenea/biblioteca/77136.pdf

Paniagua-Suárez R., Gonzalez-Posada C., \& Montoya-Gómez B. (2010). Three typologies for adolescents mental health in north-eastern Medellín, Colombia, 2006. Rev. salud pública, 12(1), 51-60.

Pellegrini LC., \& Rodriguez-Mongui R. (2013). Unemployment, Medicaid provisions, the mental health industry, and suicide. The Social Science Journal, 50(4), 482-490. http://dx.doi.org/10.1016/j.soscij.2013.09.013

Pérez-Olmos I., Téllez DL., Vélez AL., \& Ibáñez-Pinilla M. (2012). Caracterización de factores asociados con comportamiento suicida en adolescentes estudiantes de octavo grado, entres colegios bogotanos. Revista Colombiana de Psiquiatría, 41(1), 26-47.

Pulido A., Higuera D., Ortega T., \& Salamanca N. (2009). Seguimiento al sector salud en Colombia. Tendencias de la salud en Colombia. Colombia: Programa "Así vamos en Salud". Retrived from http://www.asivamosensalud.org/media/santafe/publicacion/027e8963b9e6cf9d65df7c7f53b8c380.pdf

Rajkumar AP., Brinda EM., Duba AS., Thangadurai P., \& Jacob KS. (2013). National suicide rates and mental health system indicators: An ecological study of 191 countries. International Journal of Law and Psychiatry, 36(5-6), 339-342. http://dx.doi.org/10.1016/j.ijlp.2013.06.004 
Ross JM., Yakovlev PA., \& Carson F. (2012). Does state spending on mental health lower suicide rates? The Journal of Socio-Economics, 41(4), 408-417. http://dx.doi.org/10.1016/j.socec.2010.10.005

Rueda GE., Rangel AM., Castro-Rueda VA., \& Camacho PA. (2010). Suicidabilidad en adolescentes, una comparación con población adulta. Revista Colombiana de Psiquiatría, 39(4), 683-692.

Sánchez R., \& Echeverry J. (2004). Validación de escalas de medición en salud. Rev. Salud pública, 6(3), 302-318.

Trujillo-Orrego N., Pineda DA., Arango CP., Puerta IC., Lopera F., \& Aguirre-Acevedo DC, et al. (2010). Dimensiones del fenotipo conductual del trastorno por déficit de atención/hiperactividad en adultos de familias antioqueñas utilizando la escala Wender-Utah en español. Revista de neurología, 48(8), 400-406. 